\title{
A Expedição do Maranhão: padres, instrumentos astronômicos e livros na Amazônia do século XVIII
}

\section{The Expedition to Maranhão: priests, astronomical instruments and books in Amazônia in the eighteenth century}

\author{
Paulo Sergio Bretones \\ Professor adjunto do Departamento de Metodologia de Ensino/Universidade Federal de São Carlos. \\ bretones@ufscar.br
}

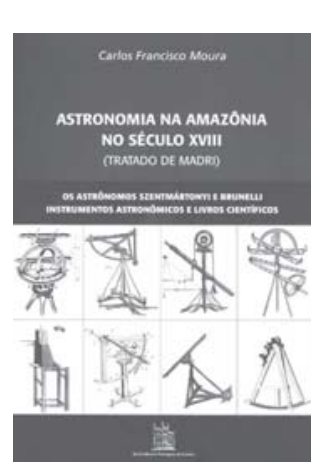

MOURA, Carlos

Francisco. Astronomia na Amazônia no século XVIII (Tratado de Madri): os astrônomos Szentmártonyi e Brunelli - instrumentos astronômicos e livros científicos. Rio de Janeiro: Real Gabinete Português de Leitura, 2008. $168 p$.
1 com grande alegria que ofereço aos leitores de História, Ciências, Saúde - Manguinhos o convite à leitura de um livro pioneiro para a história das ciências do Brasil e de Portugal. A obra, publicada pelo Real Gabinete Português de Leitura, é resultado da pesquisa desenvolvida por Carlos Francisco Moura baseada nos documentos da Expedição do Maranhão, de 1753, para demarcar os limites da Amazônia estabelecidos pelo Tratado de Madri. O objetivo desse tratado, datado de 13 de janeiro de 1750, era substituir o tratado de Tordesilhas (1494), visando determinar os limites das colônias de Portugal e Espanha na América do Sul.

De início, a capa - com seu conjunto de instrumentos - já é um chamamento à leitura do livro. Tais instrumentos, usados em astronomia no século XVIII, nos remetem a uma época em que essa ciência era muito ensinada e, com fins práticos, utilizada para a elaboração de cartas geográficas e mapas. A astronomia praticada a partir de condicionantes externos, como as necessidades de demarcação de limites de territórios, foi feita dessa forma não apenas no Brasil mas em todas as colônias dos países europeus, desde a época das grandes navegações até o início de século XX.

Registra-se a falta de fluidez do texto que, no entanto, não chega a comprometer a rica narrativa que dá conta de inúmeros aspectos sobre a expedição que articulava a astronomia com a geopolítica naquela época. Essa narrativa encontra-se bem articulada em torno de três partes, como veremos a seguir.

A primeira parte, "Instrumentos astronômicos e livros científicos destinados à 'Expedição do Maranhão'” (1753), tem início com o debate a respeito da utilização dos estudos astronômicos em Portugal, promovidos por dom João V, visando às demarcações estabelecidas pelo Tratado de Tordesilhas. O monarca contrata padres matemáticos para calcular longitudes e desenhar uma nova carta do reino, adquire instrumentos, atlas geográficos e cria um observatório astronômico. Também contrata relojoeiros, publica um tratado 
relacionado à elaboração de cartas geográficas e envia os "padres matemáticos" Soares e Capassi ao Brasil, para traçar novos mapas (p.16).

Após citar a utilização de instrumentos astronômicos como o octante - para determinação de latitude e longitude - no Brasil do início do século XVIII, Moura descreve os aparatos destinados à Expedição do Maranhão para "demarcar os confins da América" (p.21). Tais instrumentos são citados em apenas 12 linhas em um documento de 1753, com dez páginas, que apresenta a relação de todas as pessoas empregadas para fazer a demarcação. Os instrumentos são descritos e apresentados com gravuras da época, sendo: telescópios e micrômetros, óculos, relógios, quadrantes, bússolas, teodolito, estojos de matemática, grafômetro, pranchetas, barômetros, termômetros, microscópios, níveis, réguas e câmaras escuras. A seguir, o autor identifica todos os livros e autores destinados aos expedicionários, que são mais detalhados na terceira parte da obra.

A segunda parte do livro, "Os padres matemáticos Szentmártonyi e Brunelli", inicia abordando a importância do político e diplomata brasileiro Alexandre de Gusmão que, como secretário de dom João V, teve importante papel no Tratado de Madri, que legitimou a posse, pelos portugueses, do território do Brasil a oeste do meridiano de Tordesilhas.

Em seguida, o livro menciona os ordenados pagos a cada um dos "padres matemáticos" ou "padres astrônomos", os quais, juntamente com os engenheiros contratados, tiveram que esperar em Lisboa desde agosto de 1750 até junho de 1753, quando partiram de Portugal. São apresentados também detalhes da viagem da frota que levou os astrônomos e engenheiros das demarcações, que saiu de Belém da foz do Tejo em 7 de junho e chegou em Belém do Pará em 20 de julho de 1753.

Sobre o padre Giovanni Angelo Brunelli, são discutidas as circunstâncias da sua contratação com base em um manuscrito de sua autoria em que pedia que fossem cumpridas as condições estabelecidas em Bolonha para vir ao Brasil. No documento, o padre menciona que não entendia porque, em vez dele, fora escolhido "um simples engenheiro" para ser o diretor geral já que, para a construção da carta geográfica, tudo o que podia fazer o medidor prático ou engenheiro agrimensor também podia fazer o matemático, com maior fundamento, como a determinação de longitude e latitude (p.55). Também não concordava o clérigo que outras pessoas ganhassem os créditos pela feitura da carta, uma vez que ela dependia das suas observações. Outro aspecto que questionava dizia respeito ao pagamento dos engenheiros, quase idêntico ao seu. Tais engenheiros, não tão competentes, segundo seu julgamento, tiveram novas vantagens acordadas, depois de estar juntos em Lisboa, quando Brunelli também teve que ensinar a prática das observações astronômicas aos seus companheiros matemáticos. No documento, o matemático pondera que sua honra e sua reputação não lhe permitiam que embarcasse para o Brasil sem que lhe fossem entregues bons instrumentos, prometidos quando foi contratado: quadrante, relógios, telescópio e micrômetros. Além disso, ele também exige um ajudante.

As reclamações de Brunelli também são mencionadas em cartas do padre Alexandre Ratta ao cardeal Valenti, nas quais discute a escolha dos professores, agrimensores e engenheiros militares, que foram ensinados por Brunelli, chamado de "Il Bolognese". Discute a finalidade da expedição e a possibilidade de ser bem-sucedida, pois era determinada a medir o território que a Espanha cederia à Coroa portuguesa. Para ele, os limites 
permaneceriam no escuro, sujeitos a alguma questão e, para conseguir êxito, seriam necessários bons astrônomos.

Nesse contexto, menciona o engenheiro e agrimensor coronel Blasco, tido como chefe principal da operação, considerando, segundo sua comparação, que era o mesmo que dizer que o médico operasse sob a direção do barbeiro e fosse subordinado a ele.

Ainda em Lisboa, Brunelli participou do programa internacional de observações astronômicas, coordenado pelo astrônomo francês La Caille, juntamente com outros astrônomos portugueses e estrangeiros que lá se encontravam na ocasião. Durante dois anos, observou três eclipses da Lua e não teria sido bem-sucedido, queixando-se do local em que fazia as observações e da falta de instrumentos.

Sobre Brunelli na Amazônia, o livro transcreve trechos de cartas trocadas entre autoridades portuguesas e Mendonça Furtado, governador do Grão-Pará e Maranhão, que elogiam o padre e solicitam apoio a ele e a seu ajudante, tratam do relacionamento e de sua competência na profissão. Em outubro de 1754, parte de Belém a expedição comandada pelo governador Mendonça Furtado conduzindo os astrônomos e engenheiros para o arraial de Mariuá, no alto rio Negro, onde esperou inutilmente a chegada da comissão espanhola, voltando para Belém em dezembro de 1758.

Em fevereiro de 1761 é assinado o Tratado do Pardo, entre Portugal e Espanha, que anula o Tratado dos Limites de 1750 e suspende as demarcações. Dessa forma, Brunelli retorna a Lisboa em junho de 1761. De volta a Portugal, é nomeado professor de matemática do Real Colégio dos Nobres de 1767 a 1769, sendo o mais bem pago. Foi nessa época que traduziu a obra Elementos, de Euclides, publicada em Lisboa em 1768.

Brunelli solicita licença por problema de saúde em 1769 a fim de viajar para Gênova, mas retorna a Portugal e, em 1779, com a criação da Academia Real de Marinha, passa a lecionar naquela instituição. Em 1791 já estava jubilado e veio a falecer em 25 de fevereiro de 1804, em Portugal.

Várias de suas obras sobre matemática e geometria e duas dissertações sobre a aurora boreal, lidas na Academia de Bolonha, foram adquiridas pela Real Biblioteca do Rio de Janeiro em 1818, compradas de José da Costa e Silva, que foi educado por Brunelli e viajou com ele para Bolonha, onde estudou e, após voltar a Portugal, lecionou desenho e arquitetura. Chegando ao Brasil em 1818, Costa e Silva foi nomeado arquiteto geral de todas as obras da corte.

Para aqueles interessados na vida e obra do matemático Brunelli, a Biblioteca Nacional do Rio de Janeiro publicou em 1966 um inventário dos documentos da coleção Brunelli, sobre sua correspondência. Alguns de seus trabalhos são decorrentes de sua vivência na Amazônia durante oito anos, quando pesquisou muitos assuntos como a ciência física, a história natural e os costumes do povo.

Sobre o astrônomo croata e jesuíta Ignác Szentmártonyi, o livro discute as circunstâncias da sua contratação com base em uma publicação de Anselmo Eckart, que também foi missionário na Amazônia. A contratação de astrônomos ou matemáticos jesuítas era uma preferência de dom João $\mathrm{V}$ para as comissões de demarcação, e Brunelli só foi contratado por não se ter conseguido outro matemático jesuíta que aceitasse trabalhar no Brasil. 
O livro faz referência à viagem de Szentmártonyi ao Brasil e à carta de Mendonça Furtado, com impressões a respeito do astrônomo e de suas observações em Macapá, onde, em 1754, observou o eclipse da Lua para determinar a diferença de longitude entre essa vila e Belém. O autor apresenta detalhes da viagem de Belém a Mariuá e o ensino de astronomia a João Wilckers, nomeado engenheiro-ajudante, que praticava e aprendia com Szentmártonyi.

Para a demarcação do trecho considerado de maior responsabilidade, entre os rios Madeira e Guaporé, foi escolhido Szentmártonyi, também elogiado por Mendonça Furtado. São mencionados vários trabalhos cartográficos que contaram com as suas observações astronômicas, como às referentes aos rios Amazonas e Negro.

O livro também menciona detalhes da prisão de Szentmártonyi e outros, decorrente da expulsão dos jesuítas de Portugal e seus domínios. Preso em Ibirajuba em julho de 1760, embarcou em setembro e chegou em dezembro em Portugal, indo para as masmorras do forte de São Julião da Barra. Após alguns meses, foi transferido para o cárcere do Azeitão e, oito anos depois, em 1769, voltou às prisões de São Julião. Somente em 1777, com a morte de dom José I e a queda do marquês de Pombal, Szentmártonyi e outros 44 jesuítas foram libertados. São transcritos trechos do livro de Eckart mencionando o regresso à pátria. Não se pode deixar de notar certa ironia de Eckart ao abordar a remuneração que Szentmártonyi recebeu pelos serviços prestados ao rei em Portugal e no Brasil - um cativeiro de 17 anos, dizia ele. Carlos Francisco Moura considera que há dúvidas sobre o ano da morte de Szentmártonyi, se 1793 ou 1806, o que espera que seja esclarecido em futura publicação.

A obra também trata das observações astronômicas realizadas em meados do século XVIII. Explica o conceito de latitude e sua determinação pelos pilotos portugueses desde o século XV, com o uso de quadrantes e astrolábios para medir a altura do polo. Aborda o problema do estabelecimento da longitude, que dependia de instrumento confiável para medida do tempo, o que só foi resolvido com os relógios de pêndulo, no século XVII, para determinações em terra, e com o cronômetro, no século XVIII, para viagens que usavam embarcações.

Moura explica o uso dos eclipses da Lua e, posteriormente, os eclipses dos satélites de Júpiter para determinação de longitude, pelo fato de que estes fenômenos são observados em diferentes locais e no mesmo instante, porém, em horas diferentes para cada local. Tais fenômenos são previstos e disponíveis em tabelas de efemérides calculadas pelos astrônomos.

Para a determinação de longitudes, Szentmártonyi tomou como origem o meridiano da ilha do Ferro. A obra descreve ainda as instruções de dois astrônomos espanhóis para o cálculo da longitude pela observação dos satélites de Júpiter e com a utilização de um relógio de pêndulo.

O livro apresenta o fac-símile e a transcrição de trecho de uma carta de julho de 1755 do governador Mendonça Furtado, encaminhando as observações astronômicas feitas pelos padres matemáticos em que são citados instrumentos usados como o telescópio e o quadrante.

Quanto à Amazônia, a obra também publica o fac-símile das observações das latitudes, de responsabilidade de Szentmártonyi, desde Belém até Mariuá, bem como as determinações de longitudes, variações da agulha, termômetro e barômetro. 
Deve-se destacar a menção aos eclipses da Lua de 1753, 1754 e 1755 usados para determinações de longitude.

Finalmente, a terceira parte, "Livros e autores que constam na lista da 'Expedição do Maranhão' (1753)", refere-se aos livros já mencionados na primeira parte da obra.

Segundo o autor, da mesma forma que os instrumentos, os livros foram escolhidos sob a coordenação de Alexandre de Gusmão. São mencionados vinte livros, com a reprodução de suas folhas de rosto e respectivos resumos biobibliográficos dos seus autores, como: Tratado de Madri, Lisboa, 1750, nas versões portuguesa e espanhola; Observaciones astronomicas $y$ phisicas, Madri, 1773, de dom Jorge Juan e dom Antonio de Ulloa; La Figure de la Terre, de Bouguer, Paris, 1749; Ephemerides motuum coelestium, de Zanotti, Bononiae, 1750; Astronomie nautique, de Maupertius, Paris, 1751; Traité de la construction des instruments de mathématique, de Bion, Paris, 1752; Elements d'astronomie, de Cassini, Paris, 1740, entre outros.

Além dos textos agrupados nas três partes aqui mencionadas, existe uma cronologia de 1494, ano do Tratado de Tordesilhas, até 1818, quando a Real Biblioteca adquire obras que pertenceram a Brunelli.

Espera-se que essa obra pioneira possa estimular futuras pesquisas sobre a ainda pouco conhecida história da astronomia do século XVIII. 